\title{
Determinants of Consumer Perceptions toward Mobile Advertising - A Comparison between Japan and Austria
}

\author{
Chia-Ling 'Eunice’ Liu, ${ }^{\text {a }}$ Rudolf R. Sinkovics, ${ }^{\mathrm{b}, *}$ Noemi Pezderka ${ }^{\mathrm{b}} \&$ Parissa Haghirian ${ }^{\mathrm{c}}$ \\ ${ }^{a}$ Department of Business Administration, School of Management, National Cheng Kung University, Tainan, 70101 Taiwan, ROC \\ ${ }^{\mathrm{b}}$ The University of Manchester, Manchester Business School, Booth Street West, Manchester M15 6PB, UK \\ ${ }^{\mathrm{c}}$ International Management, Sophia University, Faculty of Liberal Arts, 102-8554 Tokyo, 7-1 Kioi-cho, Chiyoda-ku, Japan
}

Available online 9 September 2011

\begin{abstract}
Mobile marketing provides an innovative channel for transmitting advertising messages to customers via mobile devices. The growth of mobile advertising in recent years requires that researchers and practitioners understand consumer perceptions of this form of advertising. The purpose of this paper is to investigate factors influencing the perception of mobile advertising in different cultures. Based on samples from Austria and Japan, we empirically examine relevant m-advertising effects. The results suggest that infotainment and credibility are key factors predicting advertising value among Austrians and the Japanese. However, our findings show that Japanese customers are more irritated by mobile advertising than are Austrian respondents.
\end{abstract}

(C) 2011 Direct Marketing Educational Foundation, Inc. Published by Elsevier Inc. All rights reserved.

Keywords: M-marketing; Mobile advertising; E-advertising; Consumer perception

\section{Introduction}

The rapid development of mobile technologies has created a new channel for marketing. The latest technological developments allow permanent Internet access via mobile devices such as mobile phones or PDAs. These advances bring up new challenges for marketers and marketing researchers. Marketing through mobile devices (m-marketing) allows for innovative forms of customer relationships and is expected to lead to the development of numerous mobile commerce-based services (Barwise and Strong 2002; Laszlo 2009; Venkatesh, Ramesh, and Massey 2003). The mobile phone has become a "portable entertainment player, a new marketing tool for retailers and manufacturers, a multichannel shopping device, a navigation tool, a new type of ticket and money, and a new mobile Intranet device" (Funk 2004, p 2). At the same time, the mobile phone has also

\footnotetext{
* Corresponding author.

E-mail addresses: clliu@mail.ncku.edu.tw (C.-L.'E.' Liu), Rudolf.Sinkovics@manchester.ac.uk (R.R. Sinkovics), noemi.pezderka@postgrad.mbs.ac.uk (N. Pezderka), p-haghir@sophia.ac.jp (P. Haghirian).
}

become an interesting channel for transmitting advertising messages to consumers. The Wireless Advertising Association (WAA) defines wireless marketing as sending advertising messages to mobile devices such as mobile phones or PDAs through the wireless network. The use of the Short Messaging Service (SMS) to access customers through their handheld devices, in particular, has been very successful (Muk 2007; Tsang, Ho, and Liang 2004). Advertisements take the form of short textual messages and are sent to customers as a form of one-to-one marketing. The rising popularity of SMS has created a new channel for mobile advertising (Barwise and Strong 2002). In terms of the types of message sent, pull SMS advertisements are displayed to consumers who have previously indicated an interest in receiving such a message and who can then decide whether to access further information (Bruner and Kumar 2007). Therefore, it is important for wireless advertisers to improve consumer response rates and acceptance of the advertising they receive. This study focuses on examining the factors influencing consumers' decisions about whether to accept pull-type SMS advertising.

Despite the growth of mobile advertising (m-advertising), few studies have empirically examined the key drivers of m-marketing 
success by pursuing a cross-cultural approach (Choi, Hwang, and McMillan 2008). One aspect of major interest is international madvertising, as mobile technology becomes a worldwide phenomenon and mobile carriers and content providers begin to have to perform on a global scale. Cross-cultural issues have so far been investigated more in the context of the "traditional" Internet. Web-based research in a cross-cultural context has revealed that a user's cultural background strongly influences his/her perception of visible advertising design elements (Marcus and Gould 2000; Park and Lee 2009; Sultan, Rohm, and Gao 2009; Wang and Sun 2010). World Wide Web advertisers have reacted to this by creating locally-oriented Web sites (Cyr and Trevor-Smith 2004). Cross-national research questions in $\mathrm{m}$-advertising have been less thoroughly investigated. Therefore, questions arise about crossnational consumer perceptions and the standardization versus adaptation of $\mathrm{m}$-advertising messages.

M-marketing activities can be performed by transferring text messages or by sending e-mails via the mobile Internet. Both Internet-based and $\mathrm{m}$-marketing activities allow personalization and interactivity. Previous research has examined consumer response to advertising and non-advertising mobile communication (Nasco and Bruner 2008), and assessed the perceived value of information and entertainment mobile services (Pihlström and Brush 2008). However, cross-cultural differences of m-marketing activities regarding dimensions such as entertainment, credibility, and advertising effectiveness have not yet received significant attention in research (Choi, Hwang, and McMillan 2008; Park and Lee 2009). To this end, this study adopts a cross-cultural perspective, specifically compares Japanese and Austrian consumers regarding m-marketing, and contributes to enhancing our understanding of this marketing tool that transcends national boundaries.

There have been several studies examining the mechanisms and influence of m-advertising (Carroll et al. 2007; Laszlo 2009; Merisavo et al. 2007). Previous research on online marketing communications has made a significant contribution toward identifying which factors influence consumers' attitudes toward advertising (Ducoffe 1996; Okazaki, Katsukura, and Nishiyama 2007; Petrovici and Marinov 2007). However, do cross-national differences influence these relationships? With this in mind, the objective of this study is to present an investigation of m-advertising across different countries. For this purpose, a study among mobile phone users was carried out in Austria and in Japan. These two countries were selected because they show a high degree of dissimilarity in cultural and historical terms. On the other hand, both countries have experienced similar levels of economic development and have comparable living standards. Furthermore, Japan and Austria are leading markets for advanced mobile technology in their geographic areas. In Japan, mobile phones started to gain popularity among young consumers as early as the mid-1990s. In 1999, market leader NTT DoCoMo launched its mobile Internet-based i-mode service, which allows mobile phone users constant access to the World Wide Web and enables subscribers to view Web pages via their mobile phones. Furthermore, subscribers can send and receive mobile e-mails and be addressed directly by advertising messages. According to the
Research of Asia (ROA) Group, the mobile user base in Japan is expected to hit 121 million users by 2011 , and the penetration rate in the Japanese market is predicted to grow to $95.4 \%$ in the same year. Mobile phones have also quickly become a new advertising tool for more than 100 Japanese retailers and manufacturers, which use the mobile Internet as an instrument to target customers with discount coupons, conduct surveys or offer free samples (Funk 2004).

Austria has one of the highest rates of mobile users in Europe. The mobile penetration rate in Austria rose to $137.4 \%$ at the end of March 2010, compared to $129.1 \%$ in the previous year, due to an increasing number of customers with SIM cards for both mobile broadband and voice services. In March 2010, the number of Austrian mobile broadband users was as high as 590,100 (Telecom Austria 2010). SMS counts for almost 13\% of mobile telecommunications revenue.

Specifically, the key research questions of this study are: (1) What factors influence the perceived value of advertising? (2) How does perceived advertising value influence consumer attitudes toward advertising? (3) Do responses to m-advertising vary across different cultures? To this end, our research contributes to the mobile communication literature by developing a conceptual framework, linking the relationships between the antecedents with the effects of m-advertising and conducting cross-national marketing research.

\section{Theoretical Background and Hypotheses}

In this study, the key concept is advertising value. The value of advertising is a critical determinant of consumer response but has received only scant attention from researchers (Ducoffe 1995; Knopper 1993). Advertising value is conceptualized as "a subjective evaluation of the relative worth or utility of advertising to consumers" (Ducoffe 1995, p 1). The study of advertising value could add to our understanding of how advertising works, a key dimension of which would be the worth of advertising to consumers (Ducoffe 1996). Innovations in new technologies create advertising opportunities and challenges. Advances in mobile phones increase the ubiquitous connectivity, frequency, and speed of communication through which timely mobile advertising can be delivered to consumers based on their demographic characteristics and geographic information (Muk 2007; Watson et al. 2002). In sum, new technologies were being developed, not for giving power to the marketers, but for empowering consumers (Deighton and Kornfeld 2009; Pires, Stanton, and Paulo 2006). Delivering permission-based message alerts to mobile phones drives more response actions, captures consumers' attention and enhances brand awareness (Barwise and Strong 2002; Yunos, Gao, and Shim 2003). The uniqueness of opt-in SMS advertising lies in its ability to filter or customize the marketer's message to target consumers in specific context (Deighton and Kornfeld 2009; Muk 2007). However, little research has been conducted to examine the consumers' beliefs in accepting permission-based advertising. The specific characteristics of local markets, along with the increasing trend for global mobile commerce, have increased the need for cross-national studies on m-marketing 
(Muk 2007). Therefore, our study attempts to identify the factors influencing advertising value and, as a result, enhance our understanding of how consumers develop favorable or unfavorable attitudes toward mobile advertising.

The uses and gratifications (U\&G) theory has been fruitful in providing an understanding of consumers' motivations and concerns in the context of traditional media, such as radio and TV (Eighmey and McCord 1998). U\&G theory was first developed in research on the effectiveness of the radio medium in the 1940s and has since been applied to explain psychological motives and consumers' value generations from various mass media such as television, electronic bulletins and wired Internet (Luo 2002; Okazaki 2004). A consensus exists that the most important and robust dimensions of $U \& G$ theory include entertainment, informativeness, and irritation (Eighmey and McCord 1998; Luo 2002; Okazaki 2004). The investigation of consumers' perspectives of m-advertising value can thus be viewed as an extension of U\&G theory. Following U\&G theory (McQuail 1983); Ducoffe's (1996) and Wright's 1974 study of Web advertising, we posit that these dimensions are also relevant to wireless Internet as information and entertainment values are usually entwined with each other in the new technological world (Wang and Sun 2010). Following previous research (Okazaki 2004; Wang and Sun 2010), informativeness and entertainment are integrated into a single construct (infotainment) in our study. In most of the previous studies, irritation is negatively related to advertising value (Korgaonkar and Wolin 1999; Okazaki 2004). The credibility of a mobile message is critical, as consumers use it to judge whether the service is believable prior to following up on the information (Choi, Hwang, and McMillan 2008; Okazaki 2005).

Our model, as shown in Fig. 1, is based on the premise that the perceived infotainment, irritation, and credibility of mobile advertisements all influence the way consumers evaluate them. The attitude toward advertising is modeled as the consequence of advertising value. Each of these factors is discussed in the following sections.

\section{The Infotainment of $m$-Advertising}

U\&G theory has recently been applied to examine e-consumer behavior associated with Web sites, and mobile phones (Luo 2002; Okazaki 2004). The consumer value attributed to advertising information can be viewed as a natural extension of $U \& G$ theory. $U \& G$ theory considers information provision as a need-satisfying function (Ducoffe 1995). Information is considered as a valuable incentive in m-marketing because recipients react very positively to the advertising (Aitken, Gray, and Lawson 2008). Informativeness is thus accounted for the "U", which is the useful part in our "infotainment" construct. It is defined as the extent to which the advertising medium provides users with resourceful and helpful information (Ducoffe 1996). Marketers generally tend to convey information via advertising messages (Gordon and De Lima-Turner 1997). In the case of mobileservices (m-services) (Pagani 2004), consumers expect the content to be tailored to their interests (Robins 2003) and to prefer messages that are relevant for them (Milne and Gordon 1993). The quality of the information placed on a company Web site has a direct influence of the customers' perceptions of the company and its products. Accordingly, the information delivered to them via mobile devices also needs to show qualitative features, such as accuracy, timeliness, and usefulness for them (Nasco and Bruner 2008). Chowdhury et al. (2006) find that consumers do not feel annoyed if mobile advertisers present advertisements with appropriate information. Scharl, Dickinger, and Murphy (2005) report that when advertisers provide funny and entertaining SMS advertising messages, which are informative and relevant to the target group, customers are likely to increase their purchasing intentions regarding the advertised products. Not surprisingly, the

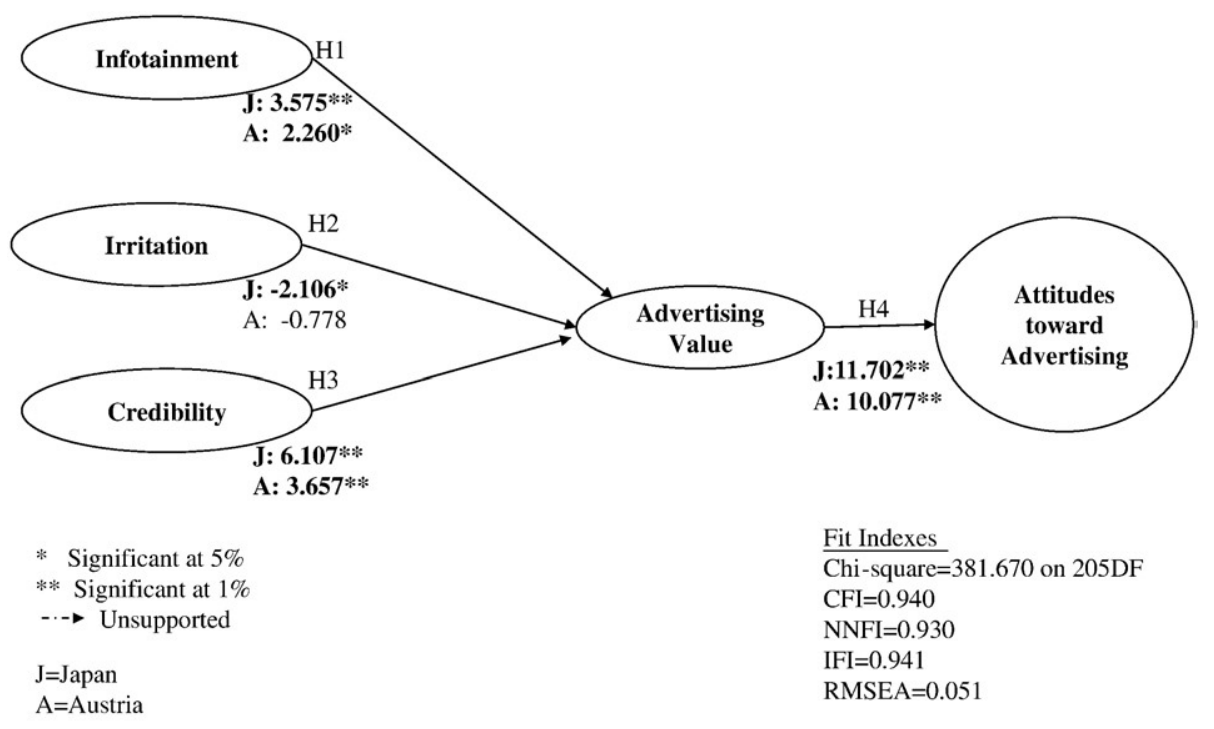

Fig. 1. Diagram of hypothesized relationships. 
informativeness of the advertising information is therefore strongly related to perceived advertising value (Ducoffe 1996).

In a related vein, uses and gratifications research has demonstrated that entertainment denotes the ability to fulfill consumers' needs for "escapism, diversion, esthetic enjoyment or emotional release" (McQuail 1983), which can be used to involve customers more deeply and make them more familiar with the advertised service or product (Lehmkuhl 2003). To this end, entertainment represents the " $G$ " element, the entertaining part of our "infotainment" construct. People's feeling of enjoyment when viewing advertisements plays the greatest role in accounting for their overall attitudes toward them (Heng, Lih-Bin, and Hock-Hai 2009; Shavitt, Lowrey, and Haefner 1998). The entertainment value of advertising information is significantly related to the perceived value of traditional advertising (Chowdhury et al. 2006; Ducoffe 1995). Entertainment services can increase customer loyalty and add value for the customer. An entertaining advertising message is therefore perceived more positively by recipients and affects their perceptions of the value of the advertising. In an information society, consumers are more likely to display a preference for "infotaining" m-advertising, which they consider useful when out and about. Therefore, we hypothesize that:

H1. The perceived infotainment of m-advertising is positively associated with perceived advertising value.

\section{Irritation Caused by m-Advertising}

Irritation has been defined as the extent to which the Web is messy and irritating to consumers (Eighmey and McCord 1998). In their study of American consumers, Bauer and Greyser (1968) indicate that the major reasons people criticize advertising are related to the annoyance or irritation it causes. Irritation may lead to a general reduction of advertising effectiveness and the value perceived by audiences (Aaker and Bruzzone 1985; Luo 2002). Most consumers are still quite uncomfortable with the concept of mobile business and skeptical about whether the businesses engaging in $\mathrm{m}$ advertising are feasible and secure (Siau and Shen 2003). Consumers can no longer depend on the intuitive sense of place and presence that governs their observable behavior, to make sure that they are not being watched or recorded by another individual (Rust, Kannan, and Peng 2002), which leads to feelings of insecurity. "When advertising employs techniques that annoy, offend, insult, or are overly manipulative, consumers are likely to perceive it as an unwanted and irritating influence" (Ducoffe 1995, p 3). M-advertising may provide information that is distracting and which overwhelms the consumer (Stewart and Pavlou 2002) and this can be perceived as an intrusion into the mobile user's privacy. Consumers then feel confused about the advertising and react negatively to it. We therefore conclude that irritation caused by incomprehensible or unwanted m-advertising messages may reflect negatively on the perceived value of $\mathrm{m}$-advertising.

H2. The irritation felt as a result of m-advertising is negatively associated with perceived advertising value.

\section{The Credibility of m-Advertising}

Advertising credibility refers to "consumers' perception of the truthfulness and believability of advertising in general" (MacKenzie and Lutz 1989, p 51). In their study, MacKenzie and Lutz suggest that there are different advertising credibility subsystems, including advertiser credibility and advertising credibility. The credibility of an advertisement is influenced by different factors, but especially the company's credibility and the bearer of the message (Goldsmith, Lafferty, and Newell 2000; Lafferty, Goldsmith, and Newell 2002). Advertiser credibility can be defined as the extent to which a customer perceives the company to be a credible source of information, and this credibility in turn assures the customer of the company's reputation, integrity, and good will (Okazaki, Katsukura, and Nishiyama 2007; Okazaki 2004). Advertising credibility is evaluated through the content the advertisements deliver. In wireless Internet communications, such credibility is vital in ensuring that the consumers acquire time-critical information, tied to a remote event or transaction (Balasubramanian, Peterson, and Jarvenpaa 2002). The relevance and credibility of advertisements are considered crucial when consumers must make decisions or take actions on the basis of uncertain information (Okazaki, Katsukura, and Nishiyama 2007). On the basis of the previous arguments, we propose that advertising credibility positively affects the perceived value of advertising. Therefore:

H3. The perceived credibility of m-advertising is positively associated with perceived advertising value.

\section{Perceived Advertising Value and Attitudes toward m-Advertising}

Values are the basis of actions, attitudes, and judgments related to advertising as well as other aspects of social life (Beatty et al. 1985). Advertising value is a measure of advertising effectiveness and "may serve as an index of customer satisfaction with the communication products of organizations" (Ducoffe 1995, p 1). A value is a "belief about some desirable end-state that transcends specific situations and guides selection of behavior" (Schwartz and Bilsky 1987). The perceived value of advertising, as outlined, is the subjective evaluation of the worth or utility of advertising. Attitudes are "mental states used by individuals to structure the way they perceive their environment and guide the way they respond to it" (Aaker, Kumar, and Day 1995, p 254). An attitude toward advertising is defined as a consumer's "learned predisposition to respond in a consistently favorable or unfavorable manner toward advertising in general" (MacKenzie and Lutz 1989, p 54) and has a major impact on their behavior (Iacobucci and Churchill 2010). Exchange, the central concept in marketing, involves the passing of value to each party (Houston and Gassenheimer 1987). An advertising message can be viewed as a potential communication exchange between advertiser and consumer (Ducoffe 1995). For exchanges to be effective, it is important to consider both parties' perspectives. The advertiser's aim is to influence the consumer's attitude about whether to purchase. Therefore, the value of any 
advertisement is evaluated against this criterion (Ducoffe 1996). To the consumer, a successful exchange is judged by whether the advertising value itself can be considered to satisfy their expectations. With the great advances in communication technologies that are expected, consumers may gradually pay for advertising they prefer and screen out the rest (Mayer 1991). One would expect that advertising that lacks value is likely to have a negative effect that will contribute to the formation of negative consumer attitudes toward advertising (Ducoffe 1996). Turning this argument around, we thus conclude that a high perceived value of m-advertising will reflect positively on a consumer's attitude toward m-advertising.

H4. A consumer's perception that advertising has a high value is positively associated with their attitude toward m-advertising.

\section{Cultural Influences - A Cross-Country Comparison}

Culture is defined as "the interactive aggregate of common characteristics that influence a group's response to its environment" (Hofstede 1980, p 19). Culture is considered the most important factor that influences consumer behavior and international marketing on the Internet (Shankar and Batra 2009). Culture and advertising are inherently related (Wang and Sun 2010). Over the past decade, cultural influences on consumers' beliefs and attitudes toward advertising have been examined in the marketing literature (La Ferle, Edwards, and Lee 2008; Rustogi, Hensel, and Burgers 1996). For example, Durvasula and Lysonski (2001) conducted a multicultural investigation of consumers' attitudes toward advertising and concluded that beliefs toward advertising are different across cultures. In a recent study, Wang and Sun (2010) compared attitudes toward advertising in China and Romania. They found that Romanians tended to hold a more positive attitude toward online advertising, whereas the Chinese were more likely to buy online than the Romanians. Extending this line of research into the m-advertising environment, this study intends to investigate the moderating effects of national culture.

It might be enlightening to employ Hofstede's (2001) and Hall's (1976) frameworks of cultural dimensions to analyze the effects of national culture. There are important differences between Japan and Austria along the major cultural dimensions: individualism/collectivism, uncertainty avoidance, power distance (Hofstede 2001) and high/low-context (Hall 1976). Japan has the cultural characteristics of collectivism, high uncertainty avoidance, high power distance (Hofstede 1991), and of being high-context (Hall 1976). In contrast, Austria has the cultural characteristics of individualism, low uncertainty avoidance, low power distance (Hofstede 1991), and is a low-context culture (Hall 1976). Individualism/collectivism is defined as the relationship between the individual and the collective that prevails in a particular society (Hofstede 2001, p 213). Uncertainty avoidance refers to the degree to which people are tolerant of uncertainties (Wang and Sun 2010). Power distance explains the degree of hierarchical power distribution in a society (Hofstede 2001). Consumers in low-context cultures prefer direct and explicit information (Hall 1976), while those from high-context cultures prefer indirect and circular communication patterns (Hall 1976).

Japanese mobile carriers, right from the start of the mobile Internet, have very strongly promoted its use as a means of entertainment. In contrast, in Europe and the US, mobile Internetbased services are strongly positioned as a convenient service for business professionals and mainly provide business-related information (Funk 2004). Advertising in Japan is generally more fantasy-oriented than advertisements in Western countries. Japanese advertisements avoid logic and are often implicit, intuitive, and emotional rather than rational (Johansson and Nonaka 1996). This is also the case in m-advertising. Consequently, Japanese consumers no longer regard their mobile phones as mere communication tools, but as portable entertainment players (Haghirian, Dickinger, and Kohlbacher 2004) and also perceive the advertising messages they receive through them as more entertaining than do their Western counterparts. In contrast to Europeans, the Japanese prefer information to flow freely (Hall and Hall 1987). Information has an important role to play in Japanese society. A greater amount of it is collected and transmitted within Japanese society than in Western society, due to the fact that the Japanese are avid information gatherers, mainly in order to minimize downside risks. Information in Japan refers to all kinds of data, including information that would not be of interest in Western countries (Johansson and Nonaka 1996). One may therefore assume that m-advertising messages are also considered a source of infotainment. Hence:

H5a. The effect of infotainment on advertising value is greater for the Japanese than for the Austrians.

The Japanese are generally considered to be members of a collectivistic culture, where information about individuals is frequently and openly shared. The Austrians, on the other hand, are members of an individualistic culture, where personal information is not freely distributed (Hall and Hall 1987; Hofstede 1980). Consumers in individualistic cultures tend to emphasize freedom, and thus hold a variety of opinions and attitudes, due to the desire to be unique. Another cultural dimension that may help to provide an understanding of consumers' attitudes is power distance. Consumers from high power distance cultures tend not to question authority and are more easily persuaded by marketing communication messages (Littrell and Valentin 2005; Wang and Sun 2010). In contrast, individuals from low power distance cultures might not accept orders from authority. They are more analytical and critical and could have more doubt about advertising messages (Wang and Sun 2010). Consumers in high power distance cultures such as Japan are thus likely to hold more positive beliefs about madvertising. Accordingly, m-advertising messages may be perceived as less irritating by Japanese consumers. Therefore, the following hypothesis is proposed:

H5b. The effect of irritation on advertising value is greater for the Austrians than for the Japanese.

According to Hofstede (1980, p 165), societies that are anxious about the future, such as Japan, actively avoid risk in 
order to create a sense of control; in other words, they have high uncertainty avoidance. Credibility should be viewed as consisting of two primary dimensions, one cognitive and one affective (Batra, Myers, and Aaker 1996). The former includes judgments about power, prestige, and competence (expertise), while the latter concerns judgments about trustworthiness and attractiveness (Okazaki 2005). Japanese consumers believe that the best advertising is represented by a satisfied product owner and thus try to establish a mutually-supportive relationship between buyer and seller (Johansson and Nonaka 1996). In Japan, subjective norms based on group conformity may influence a person's acceptance of any specific information (Barnes and Huff 2003). Given the limited space on mobile screens, the good reputation of the sponsor may influence the perceived value of mobile advertisements. Credibility also reduces the risk involved when consumers have to make decisions about unknown wireless Internet communication (Goldsmith, Lafferty, and Newell 2000). Therefore, we conclude that the Japanese perceive company communications in the form of m-advertising as more credible than do the Austrians. Accordingly, the following hypothesis is proposed:

H5c. The effect of credibility on advertising value is greater for the Japanese than for the Austrians.

\section{Research Methodology}

\section{Sample}

In order to test the hypothesized model, a standardized survey was conducted in Austria and Japan. Mobile phone owners were requested to comment, using standard scales, regarding their perceptions of pull-type SMS advertisements. The collection of the Japanese data was conducted over a fourweek period. The interviewees were undergraduate business students from two different Japanese universities. 450 questionnaires were handed out, 420 of which were returned, 170 providing usable answers for this investigation. In Austria, 600 mobile phone owners were interviewed about their perceptions. The interviewees were undergraduate business students from an Austrian university. Out of the 600 questionnaires handed out, 448 were returned, 164 of which provided usable answers. This resulted in a response rate of $37.8 \%$ in the Japanese sample and $27.3 \%$ in the Austrian sample. Table 1 provides an overview of the demographic distributions of the Japanese and Austrian samples. All interviewees were mobile phone owners and users.

Table 1

Sample description.

\begin{tabular}{|c|c|c|c|c|c|}
\hline \multicolumn{3}{|l|}{ Austrian sample } & \multicolumn{3}{|l|}{ Japanese sample } \\
\hline Age of interviewee & Female & Male & Age of interviewee & Female & Male \\
\hline & 7 & & & 17 & \\
\hline $21-25$ years & $38.19 \%$ & $38.89 \%$ & $21-25$ years & $11.66 \%$ & $31.90 \%$ \\
\hline Older than $26 y$ & $4.86 \%$ & $9.03 \%$ & Older than 26 years & $0.61 \%$ & $1.23 \%$ \\
\hline Total & $50.69 \%$ & $49.31 \%$ & Total & $29.45 \%$ & $70.55 \%$ \\
\hline
\end{tabular}

The sample can be regarded as a convenience sample and therefore is limited in its ability to provide generalizations.

The standardized questionnaire was first developed in the English language and then translated into German and Japanese by native speakers. After a back-translation approach (Brislin 1970), two pre-tests (on 30 Austrian students and 35 Japanese students) were conducted and minor adaptations regarding the wording of two of the Japanese items were made.

\section{Scale Development}

Items for infotainment, irritation, and advertising value were derived from Ducoffe's (1996) scales for advertising on the World Wide Web. The credibility scale was based on MacKenzie and Lutz's (1989) scale for advertising credibility and the scale used to measure attitudes toward m-advertising was based on Alwitt and Prabhacker's (1994) scale, which measured consumer attitudes toward television advertisements. All measures were assessed via a five-point Likert-type scale ranging from "strongly agree" (1) to "strongly disagree" (5).

\section{Data Analysis and Results}

\section{Assessment of the Measurement Model}

We used EQS 6.1 to conduct two-group confirmatory factor analysis (CFA). Before comparing the results from Japan and Austria, we followed the suggestions made by Steenkamp and Baumgartner (1998) to examine the cross-national invariance of the measurement instruments (Brown 2006; Steenkamp and Baumgartner 1998). Firstly, the configural invariance was tested. Configural invariance of the five constructs was supported as the CFA results showed a good fit $(\mathrm{CFI}=0.943)$ and all parameter estimates were significantly loaded on the respective factors. Secondly, metric invariance was tested, that is we constrained all factor loadings to be invariant across countries. The results showed that all factors have full metric invariance except for advertising value, which revealed partial metric invariance with one item in addition to the fixed item that was invariant across the groups. We followed the procedures suggested by Steenkamp and Baumgartner (1998) to release the invariance constraints step by step, according to the modification indices and expected parameter changes. Finally, a partial metric invariance model, with one of the 16 invariance constraints relaxed, was supported. As shown in Table 2, the final CFA model revealed a good fit with the covariances

Table 2

Test for measurement invariance.

\begin{tabular}{llllll}
\hline & Chi-square & df & CFI & IFI & RMSEA \\
\hline Non-restricted model & 355.929 & 188 & 0.943 & 0.944 & 0.052 \\
Full metric invariance & 378.019 & 204 & 0.941 & 0.942 & 0.051 \\
Partial metric invariance & 370.971 & $203^{\text {a }}$ & 0.943 & 0.944 & 0.050 \\
\hline
\end{tabular}

a Note: The invariance constraint of one item of advertising value-"SMS advertising is useful" was released. 
Table 3

Reliability and factor loadings of scale items.

\begin{tabular}{|c|c|c|c|c|c|c|}
\hline \multirow[t]{2}{*}{ Items } & \multicolumn{3}{|c|}{ Japanese sample $(\mathrm{n}=170)$} & \multicolumn{3}{|c|}{ Austrian sample $(\mathrm{n}=164)$} \\
\hline & $\begin{array}{l}\text { Factor } \\
\text { loadings }\end{array}$ & $\begin{array}{l}\text { Composite } \\
\text { reliability }\end{array}$ & AVE & $\begin{array}{l}\text { Factor } \\
\text { loadings }\end{array}$ & $\begin{array}{l}\text { Composite } \\
\text { reliability }\end{array}$ & AVE \\
\hline Infotainment & & 0.87 & 0.58 & & 0.88 & 0.58 \\
\hline SMS advertising is entertaining & 0.75 & & & 0.79 & & \\
\hline SMS advertising is enjoyable & 0.79 & & & 0.80 & & \\
\hline SMS adverting is pleasing & 0.67 & & & 0.73 & & \\
\hline SMS advertising is a good source of information & 0.76 & & & 0.75 & & \\
\hline SMS advertising is a good source of up to date product information & 0.82 & & & 0.76 & & \\
\hline Irritation & & 0.72 & 0.57 & & 0.70 & 0.54 \\
\hline SMS advertising is annoying & 0.63 & & & 0.71 & & \\
\hline SMS advertising is irritating & 0.86 & & & 0.76 & & \\
\hline Credibility & & 0.80 & 0.57 & & 0.81 & 0.59 \\
\hline SMS advertising is convincing & 0.76 & & & 0.77 & & \\
\hline SMS advertising is believable & 0.75 & & & 0.77 & & \\
\hline SMS advertising is credible. & 0.75 & & & 0.76 & & \\
\hline Advertising value & & 0.79 & 0.56 & & 0.80 & 0.57 \\
\hline SMS advertising is useful & 0.86 & & & 0.81 & & \\
\hline SMS advertising is valuable & 0.59 & & & 0.67 & & \\
\hline SMS advertising is important & 0.76 & & & 0.78 & & \\
\hline Attitudes toward advertising & & 0.83 & 0.63 & & 0.87 & 0.68 \\
\hline SMS advertising helps raise our standard of living & 0.81 & & & 0.83 & & \\
\hline SMS helps me to find products that match my personality and interests & 0.82 & & & 0.87 & & \\
\hline SMS Advertising helps me buy the best brand for a given price & 0.74 & & & 0.78 & & \\
\hline \multicolumn{7}{|l|}{ CFA model goodness of fit indexes: } \\
\hline Chi-square on $203 \mathrm{df}$ & 370.971 & & & & & \\
\hline CFI & 0.943 & & & & & \\
\hline IFI & 0.944 & & & & & \\
\hline RMSEA & 0.050 & & & & & \\
\hline
\end{tabular}

provided by the dataset, with $\chi^{2}(203)=370.971(\mathrm{p}<0.001)$, $\mathrm{CFI}=0.943$, IFI $=0.944$, and $\mathrm{RMSEA}=0.050$.

The results of the measurement model are reported in Table 3. Although the overall $\chi^{2}$ statistic for the measurement model is significant, this might be due to this test's sensitivity to sample size (Bagozzi and Yi 1988; Stump and Heide 1996). However, the ratio of $\chi^{2}$ to degrees of freedom $(1.82$, less than 3$)$ corresponds to a satisfactory fit (Hair et al. 2010). Overall, the measurement model represents a good fit with the data. The other goodness-of-fit indices suggest a good fit of the confirmatory measurement model: $\mathrm{CFI}=0.943$, NNFI $=0.933, \mathrm{IFI}=0.944$, and $\mathrm{RMSEA}=0.050$. An inspection of composite reliability for the five constructs in each of the two groups reveals that all of the coefficients are greater than
0.70, which indicates acceptable reliability (Nunnally 1978). Convergent validity was computed using Fornell and Larcker's (1981) formula and evaluated based on the significance of the factor loadings and shared variance. All factor loadings were significant for both the Japanese data and the Austrian data and greater than 0.59 for the Japanese sample and 0.67 for the Austrian sample. Therefore, the constructs demonstrate sufficient convergent validity.

We also used Fornell and Larcker's (1981) test to assess discriminant validity. They recommend the use of average variance extracted, which should be greater than the variances shared between the constructs. The comparison is usually made in a correlation matrix.

Table 4

Correlation matrix.

\begin{tabular}{llllll}
\hline & $(1)$ & $(2)$ & $(3)$ & $(4)$ & $(5)$ \\
\hline (1) Infotainment & $\mathbf{0 . 7 6 / 0 . 7 6}$ & -0.37 & 0.70 & 0.75 & 0.34 \\
(2) Irritation & -0.48 & $\mathbf{0 . 7 5 / 0 . 7 4}$ & -0.32 & -0.34 & 0.35 \\
(3) Credibility & 0.64 & -0.40 & $\mathbf{0 . 7 5 / 0 . 7 7}$ & 0.71 \\
(4) Advertising value & 0.71 & -0.51 & 0.68 & $0.75 / 0.76$ \\
(5) Attitudes toward advertising & 0.68 & -0.44 & 0.72 & 0.68 & 0.62 \\
\hline
\end{tabular}

Note: Diagonal terms (in bold) are the square roots of the average variance extracted. Off-diagonal terms are the correlations between latent constructs. Construct correlations for the Japanese and Austrian samples appear below and above the diagonal, respectively. The discriminant validity of the constructs is tested according to Fornell and Larcker's (1981) suggestions. The diagonal term must be greater than any of the elements in the row or the column corresponding to that number. 
Table 4 provides the correlation coefficients between constructs, in the off-diagonal elements of the matrix, and the square roots of the average variance extracted, calculated for each construct, along the diagonal. The discriminant validity of a construct is adequate when its diagonal element is greater than the off-diagonal elements in the corresponding rows and columns. The results indicate that the constructs had adequate discriminant validity. With respect to software implementation, the EQS program will flag the parameters that are deemed to be linearly dependent on other parameters in the model and allow the problem to be alleviated through the adjustment of a tolerance level (Kaplan 1994, p 22). There is no indication of multicollinearity from the EQS diagnostics.

\section{National-Level Analysis of the Structural Model}

To test the hypotheses of the proposed model (see Fig. 1), all measurement items from the two-group CFA model were estimated. We conducted a combined analysis where the loadings and other parameters were constrained to be equal across the groups, but the path coefficients were allowed to vary. Table 5 reports the parameter estimates and goodness-of-fit indicators of the structural equation model for the two groups. The path from infotainment to advertising value (H1) is significantly supported in both groups ( $\mathrm{t}=3.575, \mathrm{p}<0.01$ for Japan and 2.260, $\mathrm{p}<0.05$ for Austria). The hypothesized relationship between irritation and advertising value (H2) is found to be negative and significant $(\mathrm{t}=-2.106, \mathrm{p}<0.05)$ in Japan but not significant in Austria. The paths from credibility to advertising value (H3) are statistically significant $(p<0.01)$ for both samples $(t=6.107, p<0.01$ for Japan and 3.657, $\mathrm{p}<0.01$ for Austria). That is, the greater (the smaller) the degree of credibility, the greater (the smaller) the perceived value of advertising. The support for $\mathrm{H} 4(\mathrm{t}=11.702$ for the Japanese data and 10.077 for the Austrian data) confirms the assertion that the perceived value of advertising enhances consumers' attitudes toward advertising. As is shown in Table 5, H1, H3 and H4 are fully supported in both groups, while $\mathrm{H} 2$ is supported only in the Japanese sample. Although the chi-square statistic is significant $\left(\chi^{2}=381.670\right.$; degrees of freedom $(\mathrm{df})=205$; $p$-value $<0.001)$, the sufficiently low ratio of chi-square to degrees of freedom (1.86, less than 3 ) indicates a satisfactory fit. Furthermore, the final results reveal a good fit $(\mathrm{CFI}=0.940 ; \mathrm{NNFI}=0.930 ; \mathrm{IFI}=0.941 ; \mathrm{RMSEA}=0.051)$. Therefore, the hypothesized model is a reasonable representation of the data.

\section{Multigroup Analysis}

In the next phase of the analysis, the two-group comparison of structural equation modeling was applied to test the moderating effects. First, we estimated the two-group model, with all three equality constraints between the groups for the moderators specified. Then, we estimated three additional models with one of the equality constraints released in each, to calculate the chisquare differences. The results of the multigroup analysis are given in Table 6. The multigroup tests $(\mathrm{H} 5 \mathrm{a}-\mathrm{H} 5 \mathrm{c})$ reported significant differences among the three path coefficients and between the two countries. Infotainment has a greater effect on advertising value in Japan than in Austria $\left(\Delta \chi^{2}=4.156, \mathrm{df}=1\right.$, $\mathrm{p}=0.041)$. Therefore, H5a is supported. In terms of the effects of credibility on advertising value, the results show that credibility has a greater influence in Japan than in Austria $\left(\Delta \chi^{2}=6.66 \mathrm{df}=1\right.$, $\mathrm{p}=0.009$ ), supporting H5c. However, irritation has a negative and greater impact in Japan $(\mathrm{t}=-2.106, \mathrm{p}<0.05)$ than in Austria $((t=-0.778, p>0.05))$, against our expectations. Thus, H5b is not supported. Fig. 1 summarizes the results of our hypothesis tests.

\section{Discussions and Conclusions}

\section{Links among the Antecedents, Advertising Value, and Attitudes toward m-Advertising}

This study contributes to the understanding of three antecedents that influence the perceived value of advertising in Japan and Austria: infotainment, irritation and credibility. Among these three factors, the links between infotainment and credibility and the perceived value of advertising were supported in both the Japanese and Austrian samples. When consumers believe that $\mathrm{m}$ advertising is credible and trustworthy, they tend to have favorable perceptions about the value of advertising. This seems to be consistent with some previous studies on advertising (Goldsmith, Lafferty and Newell 2000; Okazaki 2004; Wang and Sun 2010): credibility is one of the crucial factors in establishing the customer-client relationship. Next, the perceived value of advertising was found to be the most important determinant of consumers' attitudes toward advertising.

Providing information is one of the most important functions of advertising. In a competitive market place, advertisements need to be interesting and enjoyable to catch audiences' attention. Entertainment establishes an emotional link with customers and a brand message and is thus an important factor

Table 5

Structural parameter estimates and model fit indices (National Level Analysis).

\begin{tabular}{|c|c|c|c|c|c|c|}
\hline \multirow[t]{2}{*}{ Paths } & \multicolumn{3}{|l|}{ Japanese sample } & \multicolumn{3}{|l|}{ Austria sample } \\
\hline & Parameter estimates & t-values & Hypothesis & Parameter estimates & t-values & Hypothesis \\
\hline Infotainment $\rightarrow$ advertising value (H1) & 0.112 & $3.575 * *$ & Supported & 0.126 & $2.260^{*}$ & Supported \\
\hline Irritation $\rightarrow$ advertising value (H2) & -0.085 & $-2.106^{*}$ & Supported & -0.062 & -0.778 & Unsupported \\
\hline Credibility $\rightarrow$ advertising value $(\mathrm{H} 3)$ & 0.116 & $6.107 * *$ & Supported & 0.122 & $3.657 * *$ & Supported \\
\hline Advertising value $\rightarrow$ attitude toward advertising (H4) & 0.068 & $11.702 * *$ & Supported & 0.074 & $10.077 * *$ & Supported \\
\hline
\end{tabular}

Note: $*=\mathrm{p}<0.05, * *=\mathrm{p}<0.01$.

Model fit indices:

Chi-square $=381.670$ on 205 df; -value $<0.001 ; \mathrm{CFI}=0.940 ; \mathrm{BBNNFI}=0.930 ; \mathrm{IFI}=0.941 ; \mathrm{RMSEA}=0.051$. 
Table 6

Results of the multigroup comparison.

\begin{tabular}{|c|c|c|c|c|}
\hline Paths & Hypothesis moderating effect & Multigroup comparison & Path estimates Japan/Austria & Chi-square difference test $(\mathrm{df}=1)$ \\
\hline Infotainment $\rightarrow$ advertising value ( $\mathrm{H} 5 \mathrm{a})$ & Japan $>$ Austria & Japan $>$ Austria & $\begin{array}{l}0.112\left(\mathrm{t}=3.575^{* *}\right) \\
0.126(\mathrm{t}=2.260 *)\end{array}$ & $4.156^{*}(\mathrm{p}=0.041)$ \\
\hline Irritation $\rightarrow$ advertising value (H5b) & Japan $<$ Austria & Japan $>$ Austria & $\begin{array}{l}-0.085(\mathrm{t}=-2.106 * *) \\
-0.062(\mathrm{t}=-0.778)\end{array}$ & $5.403 *(\mathrm{p}=0.020)$ \\
\hline Credibility $\rightarrow$ advertising value (H5c) & Japan $>$ Austria & Japan $>$ Austria & $\begin{array}{l}0.116(\mathrm{t}=6.107 * *) \\
0.122\left(\mathrm{t}=3.657^{* *}\right)\end{array}$ & $6.66^{* *}(\mathrm{p}=0.009)$ \\
\hline
\end{tabular}

Note: $*=\mathrm{p}<0.05, * *=\mathrm{p}<0.01$.

in effective advertising (Cauberghe and De Pelsmacker 2010). The results show that the link between infotainment and the perceived value of advertising was supported in both groups.

Regarding irritation, people tend to view m-advertising negatively. Advertising has been criticized for promoting needs and desires that consumers may not have previously recognized and for creating insecurity and greed in society (Wang and Sun 2010). Past literature has established that irritation negatively affects advertising value and attitudes toward World Wide Web advertising (Ducoffe 1996; Luo 2002). However, our results show that the negative effect of irritation on advertising value was significantly supported only in the Japanese sample. In the Austrian sample, although the sign of the result was consistent with what was expected, the hypothesis was not significantly supported. The results of our survey showed that the Japanese consumers received on average 16.6 advertising messages on their mobile phones per week, whereas the Austrian consumers received only 4.11 messages per week. These differences indicate that advertising via the mobile Internet has become a very popular marketing tool for advertisers in Japan. This might also influence the respondents' perceptions of the irritation caused by m-advertising.

The results also show that the perceived value of advertising positively and significantly predicted consumers' attitudes toward $\mathrm{m}$-advertising in both groups. Perceived advertising value is considered to be a narrower construct than attitudes toward advertising, the former being a cognitive reaction about the extent to which advertising gives the consumer what they want (Ducoffe 1996, p 24). Our findings suggest that consumers rating high for their perceptions of the value of advertising were more likely to have favorable attitudes toward advertising. This is also consistent with previous literature about consumers' attitudes to advertising (Ducoffe 1996; Petrovici and Marinov 2007; Tsang, Ho, and Liang 2004).

\section{The Implication of Cross-Country Differences}

One major objective of this paper was to understand the crossnational differences in consumers' perceptions of advertising value. The findings demonstrate some significant differences between the Japanese and Austrian samples. Our multigroup analysis shows that the impact of infotainment on the perceived value of advertising is higher for the Japanese sample than for the Austrian sample. This finding is consistent with our prediction in H5a.
Our comparison also shows that the impact of irritation is higher for the Japanese sample than for the Austrian sample. This means that Japanese consumers are more sensitive to $\mathrm{m}$ advertising than are Austrian consumers. H5b is therefore rejected. This outcome is quite surprising, since scientific literature generally classifies the Japanese as very grouporiented and collectivistic, sharing a large amount of information that would be considered very private by Western standards (Hall and Hall 1987). In a collective society, such as Japan, it is reasonable to expect that cross-cultural differences in power distance will influence the effectiveness of a new marketing communication tool like m-advertising. The adoption of new information technology appears to be more greatly welcomed when it is seen as a top-down decision in societies with high power distance (Yun, Park, and Ha 2008). Past research has also shown that consumers in individualistic and low power distance cultures tend to view advertising as irritating, misleading and promoting materialism (Belch and Belch 2007). However, the assumption that Austrian consumers are more sensitive about being addressed by mobile advertisements was not supported. These results leave us with the impression that Japanese consumers, despite, or maybe because of, having been addressed by m-advertising messages for a number of years, are just as easily irritated by them, and regard them with having just as little credibility, as do the Austrian consumers. Marketing managers should therefore develop different strategies to increase advertising's appeal in both high and low power distance cultures (de Mooij 1998).

In relation to $\mathrm{H} 5 \mathrm{c}$, according to our empirical results, the impact of credibility on the perceived value of mobile advertising is higher for the Japanese sample than for the Austrian sample. The cultural dimension of uncertainty avoidance may provide a reasonable explanation for this. In comparison to Austria, the high level of uncertainty avoidance in the Japanese culture indicates that Japanese consumers would be less willing to take risks. As discussed before, credibility plays an important role in reducing consumers' worries about unsolicited mobile messages.

Our empirical results have clear implications for global marketing managers. Consumers in these two different cultures reported diverse perceptions of m-advertising. With such differences apparent, international marketers need to be cautious when they employ a centralized m-marketing approach to the global markets (Wang and Sun 2010). They could apply the preliminary insights from this study to adjust their marketing approaches to different cultures. Marketers may be able to 
achieve the maximum effect from m-advertising if they can incorporate more specific considerations for cultural differences. Otherwise, history may repeat itself: the click-through rate on wireless advertising may severely decrease over time if marketers make little effort to attract a more specific consumer target, by fitting the advertising to their real needs and wants. Poor strategies for promoting $\mathrm{m}$-advertising may lead to a considerable waste of valuable resources.

\section{Limitations and Future Research}

Despite the interesting findings and implications that were derived from this investigation, it is important to recognize its limitations and the need for additional research. The study presented here has limitations that face any cross-national research endeavor. This includes the comparability of the investigated samples, cultural differences in interpreting the survey items, and possible biases in response styles. While we account for some of these issues within the multigroup equivalence tests, not all possible biases have been accounted for. Furthermore, the mobile technology context is rapidly developing and dynamic, thus the study may not fully capture the current market situation. The emergence of mobile technologies has allowed marketers and advertisers to apply a more radically innovative advertising channel: multimedia location-based advertising ( $\mathrm{Xu}, \mathrm{Oh}$, and Teo 2009). This research would benefit from further investigation into other types of advertising that go beyond the merely text-based. Also, since this study investigates the attitudes of university students, there are arguably issues regarding its generalizability. Although today's students are quite comfortable with the use of mobile phones and have strongly integrated them into their everyday lives, it is important that we test the hypotheses on samples that represent a broader range of mobile consumers and compare $\mathrm{m}$-advertising across these different consumer profiles.

In terms of future research, the paper offers at least two major research avenues. Firstly, the relevance of the infotainment of a m-advertising message should be revisited. In contrast to Web advertising, advertising via mobile devices can provide very valuable, time- and location-oriented information for consumers, an aspect which not only strongly distinguishes it from "traditional" Web-based advertising activities, but also allows unprecedented advertising possibilities. In this research, we only test consumers' perceptions of SMS advertising. Future research, therefore, needs to clarify cross-national perceptions of the infotainment value of new types of m-advertising (for example multimedia location-based advertising). The second question that arises is the long-lasting discussion of the standardization versus adaptation of global advertising activities. Our results show that there are cross-country differences in the perceptions of m-advertising. Value perceptions and attitudes toward $\mathrm{m}$-advertising also differ. The impact of these differences on the relative benefits of standardization and adaptation needs to be further investigated in order to develop normative recommendations for advertisers and international marketing researchers. Thirdly, the framework of consumer response sequence theories states that there is a gap between attitudes and actual purchasing behaviors (Wang and Sun 2010). Our study examines the relationship between beliefs and attitudes but future research could investigate the link between attitudes and real purchasing intentions. Lastly, due to the still short history of m-advertising, consumers' perceptions of advertising value and their attitudes toward advertising may still be evolving (Karson, McCloy, and Bonner 2006; Wang and Sun 2010). A cross-sectional design might not be enough to capture this evolution. While difficult to implement, longitudinal designs are regarded as better means of understanding the dynamics and evolution of different factors.

\section{Acknowledgments}

We are grateful to Maria Madlberger and Akihiro Inoue for their helpful comments and constructive suggestions on earlier drafts. We also appreciate the constructive comments from three anonymous reviewers and the extraordinary leadership and guidance from the editor Charles Hofacker.

\section{References}

Aaker, David A. and Donald E. Bruzzone (1985), "Causes of Irritation in Advertising," Journal of Marketing, 49, 2, 47-57.

___ _ V. Kumar, and George S. Day (1995), Marketing Research. New York: John Wiley and Sons.

Aitken, Robert, Brendan Gray, and Robert Lawson (2008), "Advertising Effectiveness from a Consumer Perspective," International Journal of Advertising, 27, 2, 279-97.

Alwitt, Linda F. and Paul R. Prabhaker (1994), "Identifying who Dislikes Television Advertising: Not by Demographics Alone," Journal of Advertising Research, 34, 6, 17-29.

Bagozzi, Richard P. and Youjae Yi (1988), "On the Evaluation of Structural Equation Models," Journal of the Academy of Marketing Science, 16, 1, 74-94

Balasubramanian, Sridhar, Robert A. Peterson, and Sirkka L. Jarvenpaa (2002), "Exploring the Implications of M-Commerce for Markets and Marketing," Journal of the Academy of Marketing Science, 30, 4, 348-61.

Barnes, Stuart J. and Sid L. Huff (2003), "Rising Sun: I-Mode and the Wireless Internet," Communications of the ACM, 46, 11, 79-84.

Barwise, Patrick and Colin Strong (2002), "Permission-Based Mobile Advertising," Journal of Interactive Marketing, 16, 1, 14-24.

Batra, Rajeev, John G. Myers, and David Aaker (1996), Advertising Management. 5th ed. Upper Saddle River, NJ: Prentice Hall.

Bauer, Raymond A. and Stephen A. Greyser (1968), Advertising in America Consumer View. Boston, MA: Harvard University.

Beatty, Sharon E., Lynn R. Kahle, Pamela Homer, and Misra Shekar (1985), "Alternative Measurement Approaches to Consumer Values: The List of Values and the Rokeach Value Survey," Psychology and Marketing, 2, 3, 181-200.

Belch, George E. and Michael A. Belch (2007), Advertising in America: The Consumer View. Boston, MA.: Harvard University Press

Brislin, Richard W. (1970), "Back Translation for Cross-Cultural Research," Journal of Cross-Cultural Psychology, 1, 3, 185-216.

Brown, Timothy A. (2006), Confirmatory Factory Analysis for Applied Research. New York, NY: The Guilford Press.

Bruner, Gordon C. and Anand Kumar (2007), "Attitude toward Location-Based Advertising," Journal of Interactive Advertising, 7, 2, 3-15.

Carroll, Amy, Stuart J. Barnes, Eusebio Scornavacca, and Keith Fletcher (2007), "Consumer Perceptions and Attitudes towards SMS Advertising: Recent Evidence from New Zealand," International Journal of Advertising, 26, 1, 20.

Cauberghe, Verolien and Patrick De Pelsmacker (2010), "Advergames," Journal of Advertising, 39, 1, 5-18.

Choi, Yung Kyun, Jang-Sun Hwang, and Sally J. McMillan (2008), “Gearing up for Mobile Advertising: A Cross-Cultural Examination of Key Factors that 
Drive Mobile Messages Home to Consumers," Psychology and Marketing, $25,8,756-68$

Chowdhury, Humayun Kabir, Nargis Parvin, Christian Weitenberner, and Michael Becker (2006), "Consumer Attitude toward Mobile Advertising in an Emerging Market: An Empirical Study," International Journal of Mobile Marketing, 1, 2, 33-41.

Cyr, Dianne and Haizley Trevor-Smith (2004), "Localization of Web Design: An Empirical Comparison of German, Japanese, and United States Web Site Characteristics," Journal of the American Society for Information Science and Technology, 55, 13, 1199-208.

de Mooij, Marieke (1998), Global Marketing and Advertising: Understanding Cultural Paradoxes. Thousand Oaks, CA: Sage.

Deighton, John and Leora Kornfeld (2009), "Interactivity's Unanticipated Consequences for Marketers and Marketing," Journal of Interactive Marketing, 23, 1, 4-10.

Ducoffe, Robert H. (1995), "How Consumers Assess the Value of Advertising," Journal of Current Issues \& Research in Advertising, 17, 1, 1-18.

(1996), "Advertising Value and Advertising the Web," Journal of Advertising Research, 36, 5, 21-35.

Durvasula, Srinivas and Steven Lysonski (2001), "Are There Global Dimensions of Beliefs toward Advertising in General? A Multicultural Investigation," in Globalization and its Managerial Implications, C.P. Rao, ed.Westport, CT: Quorum Books, 184-202.

Eighmey, John and Lorla McCord (1998), "Adding Value in the Information Age: Uses and Gratifications of Sites on the World Wide Web," Journal of Business Research, 41, 3, 187-94.

Fornell, Claes and David F. Larcker (1981), "Evaluating Structural Equation Models with Unobservable Variables and Measurement Error," Journal of Marketing Research, 18, 1, 39-50.

Funk, Jeffrey L. (2004), "Key Technological Trajectories and the Expansion of Mobile Internet Applications," Info - The Journal of Policy Regulation and Strategy for Telecommunications, 6, 3, 208-15.

Goldsmith, Ronald E., Barbara A. Lafferty, and Stephen J. Newell (2000), "The Impact of Corporate Credibility and Celebrity Credibility on Consumer Reaction to Advertisements and Brands," Journal of Advertising, 29, 3, $43-54$

Gordon, Mary Ellen and Kathryn De Lima-Turner (1997), "Consumer Attitudes towards Internet Advertising: A Social Contract Perspective," International Marketing Review, 14, 5, 352-75.

Haghirian, Parissa, Astrid Dickinger, and Florian Kohlbacher (2004), "Adopting Innovative Technology - A Qualitative Study among Japanese Mobile Consumers," paper presented at the 5th International Working with e-Business conference, Perth, Australia.

Hair, Joseph F., William C. Black, Barrie J. Babin, and Rolph E. Anderson (2010), Multivariate Data Analysis - a Global Perspective. 7th ed. Upper Saddle River, NJ: Pearson.

Hall, Edward T. (1976), Beyond Culture. Garden City, N.Y: Anchor Press. and Mildred Reed Hall (1987), Hidden Differences: Doing Business with the Japanese. Garden City, N.Y: Anchor Press/Doubleday.

Heng, Xu, Lih-Bin Oh, and Hock-Hai Teo (2009), "Perceived Effectiveness of Text vs. Multimedia Location-Based Advertising Messaging," International Journal of Mobile Communications, 7, 2, 154-77.

Hofstede, Geert (1980), “Culture's Consequences: International Differences in Work-Related Values, vol. 5. Newbury Park, CA: Sage Publications.

___ (1991), Cultures and Organizations: Software of the Mind. New York: McGraw-Hill.

(2001), Culture's Consequences: Comparing Values, Behaviors, Institutions, and Organizations across Nations. 2nd ed. Thousand Oaks, CA: Sage Publications.

Houston, Franklin S. and Jule B. Gassenheimer (1987), "Marketing and Exchange," Journal of Marketing, 51, 4, 3-18.

Iacobucci, Dawn and Gilbert A. Churchill (2010), Marketing Research: Methodological Foundations. 10th ed. Mason, Ohio: South-Western Cengage Learning.

Johansson, Johnny K. and Ikujiro Nonaka (1996), Relentless: The Japanese Way of Marketing. New York: Harper Business.

Kaplan, David (1994), "Estimator Conditioning Diagnostics for Covariance Structure Models," Sociological Methods \& Research, 23, 2, 200-29.
Karson, Eric J., Samuel McCloy, and Greg P. Bonner (2006), "An Examination of Consumers' Attitudes and Beliefs towards Web Site Advertising," Journal of Current Issues \& Research in Advertising, 28, 2, $77-91$.

Knopper, Douglas (1993, April), "How About Adding Value to the Advertising Message," Advertising Age, 12, 18.

Korgaonkar, Pradeep K. and Lori D. Wolin (1999), "A Multivariate Analysis of Web Usage," Journal of Advertising Research, 39, 2, 53-68.

La Ferle, Carrie, Steven M. Edwards, and Wei-Na Lee (2008), "Culture, Attitudes, and Media Patterns in China, Taiwan, and the U.S.: Balancing Standardization and Localization Decisions," Journal of Global Marketing, $21,3,191-205$

Lafferty, Barbara A., Ronald E. Goldsmith, and Stephen J. Newell (2002), "The Dual Credibility Model: The Influence of Corporate and Endorser Credibility on Attitudes and Purchase Intentions," Journal of Marketing Theory and Practice, 10, 3, 1-12.

Laszlo, Joe (2009), "The New Unwired World: An Iab Status Report on Mobile Advertising," Journal of Advertising Research, 49, 1, 27-43.

Lehmkuhl, Frank (2003, January 6th), Kuesse und Machotests, [Online]. Munich, Germany: Focus. Available: http://www.focus.de/digital/internet/ handy-kuesse-und-machotests_aid_197719.html [Accessed: 2011, July 22].

Littrell, Romie F. and Lapadus Nicolae Valentin (2005), "Preferred Leadership Behaviours: Exploratory Results from Romania, Germany and the UK," The Journal of Management Development, 24, 5, 421-42.

Luo, Xueming (2002), "Uses and Gratifications Theory and E-Consumer Behaviors: A Structural Equation Modelling Study," Journal of Interactive Advertising, 2, 2, 34-41.

MacKenzie, Scott B. and Richard J. Lutz (1989), “An Empirical Examination of the Structural Antecedents of Attitude toward the Ad in an Advertising Pretesting Context," Journal of Marketing, 53, 2, 48-65.

Marcus, Aaron and Emilie West Gould (2000), "Crosscurrents: Cultural Dimensions and Global Web User-Interface Design," Interactions, 7, 4, 32-46.

Mayer, Martin (1991), Whatever Happened to Madison Avenue: Advertising in 1990s. Boston: Lettle, Brown and Company.

McQuail, Denis (1983), Mass Communication Theory: An Introduction. London: Sage Publication.

Merisavo, Marko, Sami Kajalo, Heikki Karjaluoto, Ville Virtanen, Sami Salmenkivi, Mika Raulas, and Matti Leppäniemi (2007), "An Empirical Study of the Drivers of Consumer Acceptance of Mobile Advertising," Journal of Interactive Advertising, 7, 2, 1-18.

Milne, George R. and Mary Ellen Gordon (1993), "Direct Mail PrivacyEfficiency Trade-Offs within an Implied Social Contract Framework," Journal of Public Policy \& Marketing, 12, 2, 206-15.

Muk, Alexander (2007), "Consumers' Intentions to Opt in to Sms Advertising," International Journal of Advertising, 26, 2, 177-98.

Nasco, Suzanne Altobello and Gordon C. Bruner (2008), "Comparing Consumer Responses to Advertising and Non-Advertising Mobile Communications," Psychology and Marketing, 25, 8, 821-37.

Nunnally, Jum C. (1978), Psychometric Theory. New York: McGraw-Hill.

Okazaki, Shintaro (2004), "How Do Japanese Consumers Perceive Wireless Ads? A Multivariate Analysis," International Journal of Advertising, 23, 4, 429-54. - (2005), "External Search, Content Credibility and Intrinsic Gratifiers Influencing Attitude toward Wirless Ads," Asia Pacific Advances in Consumer Research, 6, 7, 5-12.

___ Akihiro Katsukura, and Mamoru Nishiyama (2007), "How Mobile Advertising Works: The Role of Trust in Improving Attitudes and Recall," Journal of Advertising Research, 47, 2, 15.

Pagani, Margherita (2004), "Determinants of Adoption of Third Generation Mobile Multimedia Services," Journal of Interactive Marketing, 18, 3, 46-59.

Park, Cheol and Thae Min Lee (2009), "Antecedents of Online Reviews' Usage and Purchase Influence: An Empirical Comparison of U.S. And Korean Consumers," Journal of Interactive Marketing, 23, 4, 332-40.

Petrovici, Dan and Marin Marinov (2007), "Determinants and Antecedents of General Attitudes towards Advertising: A Study of Two EU Accession Countries," European Journal of Marketing, 41, 3/4, 307-26.

Pihlström, Minna and Gregory J. Brush (2008), "Comparing the Perceived Value of Information and Entertainment Mobile Services," Psychology and Marketing, 25, 8, 732-55. 
Pires, Guilherme D., John Stanton, and Rita Paulo (2006), "The Internet, Consumer Empowerment and Marketing Strategies," European Journal of Marketing, 40, 9, 936-49.

Robins, Fred (2003), "The Marketing of 3G," Marketing Intelligence \& Planning, 21, 6, 370-8.

Rust, Roland, P. Kannan, and Na Peng (2002), "The Customer Economics of Internet Privacy," Journal of the Academy of Marketing Science, 30, 4, 455-64.

Rustogi, Hemant, Paul J. Hensel, and Willem P. Burgers (1996), "The Link between Personal Values and Advertising Appeals: Cross-Cultural Barriers to Standardized Global Advertising," Journal of Euromarketing, 5, 4, 57-79.

Scharl, Arno, Astrid Dickinger, and Jamie Murphy (2005), "Diffusion and Success Factors of Mobile Marketing," Electronic Commerce Research and Applications, 4, 2, 159-73.

Schwartz, Shalom H. and Wolfgang Bilsky (1987), "Toward a Universal Psychological Structure of Human Values," Journal of Personality and Social Psychology, 53, 3, 550-62.

Shankar, Venkatesh and Rajeev Batra (2009), "The Growing Influence of Online Marketing Communications," Journal of Interactive Marketing, 23, 4, 285-7.

Shavitt, Sharon, Pamela Lowrey, and James Haefner (1998), "Public Attitudes toward Advertising: More Favorable than You Might Think," Journal of Advertising Research, 38, 4, 7-22.

Siau, Keng and Zixing Shen (2003), "Building Customer Trust in Mobile Commerce," Communications of the ACM, 46, 4, 91-4.

Steenkamp, Jan-Benedict E.M. and Hans Baumgartner (1998), "Assessing Measurement Invariance in Cross-National Consumer Research," Journal of Consumer Research, 25, 1, 78-90.

Stewart, David and Paul Pavlou (2002), "From Consumer Response to Active Consumer: Measuring the Effectiveness of Interactive Media," Journal of the Academy of Marketing Science, 30, 4, 376-96.
Stump, Rodney L. and Jan B. Heide (1996), "Controlling Supplier Opportunism in Industrial Relationships," Journal of Marketing Research, 33, 4, 431-41.

Sultan, Fareena, Andrew J. Rohm, and Tao Gao (2009), "Factors Influencing Consumer Acceptance of Mobile Marketing: A TwoCountry Study of Youth Markets," Journal of Interactive Marketing, 23, 4, 308-20.

Tsang, Melody M., Shu-Chun Ho, and Ting-Peng Liang (2004), “Consumer Attitudes toward Mobile Advertising: An Empirical Study," International Journal of Electronic Commerce, 8, 3, 65-78.

Venkatesh, Viswanath, V. Ramesh, and Anne P. Massey (2003), "Understanding Usability in Mobile Commerce," Communications of the ACM, 46, 12, 53-6.

Wang, Ying and Shaojing Sun (2010), "Examining the Role of Beliefs and Attitudes in Online Advertising," International Marketing Review, 27, 1, 87-107.

Watson, Richard T., Leyland F. Pitt, Pierre Berthon, and George M. Zinkhan (2002), "U-Commerce: Expanding the Universe of Marketing," Journal of the Academy of Marketing Science, 30, 4, 333-47.

Wright, Charles R. (1974), "Functional Analysis and Mass Communication Revisited," in Current Perspectives on Gratifications Research, Jay G. Blumler and Elihu Katz, eds. Beverly Hills, CA: Sage Publications, 197-212.

Xu, Heng, Lih-Bin Oh, and Hock-Hai Teo (2009), "Perceived Effectiveness of Text vs. Multimedia Location-Based Advertising Messaging," International Journal of Mobile Communications, 7, 2, 154-77.

Yun, Gi Woong, Sung-Yeon Park, and Louisa Ha (2008), "Influence of Cultural Dimensions on Online Interactive Review Feature Implementations: A Comparison of Korean and U.S. Retail Web Sites," Journal of Interactive Marketing, 22, 3, 40-50.

Yunos, Hassin M., Jerry Gao, and Simon Shim (2003), "Wireless Advertising's Challenges and Opportunities," Computer, 36, 5, 30-7. 